\title{
Inspeção da Qualidade de Habitações Populares Após Entrega
}

\author{
Inspection of the Quality of Popular Housing After Delivery
}

\author{
Bruna Maria Marques Gomes ${ }^{1}$ (i) orcid.org/0000-0003-0505-8482 \\ Ana Angélica dos Santos Faro² (D) orcid.org/0000-0001-6985-4352 \\ Taynara Matos Nascimento ${ }^{3}$ (i) orcid.org/0000-0003-1006-1424
}

\footnotetext{
1 Programa de Pós-graduação em Gerenciamento de Obras e Tecnologia da Construção, INBEC, Fortaleza, Brasil,

2 Departamento de Ciência dos Materiais; Faculdade Pio Décimo, Aracaju, Brasil,

3 Programa de Pós-graduação em Estruturas de Concreto Armado, INBEC, Aracaju, Brasil.

E-mail do autor principal: Bruna Marques brunamarquesg@gmail.com.
}

\section{Resumo}

Embora o avanço da tecnologia e dos métodos construtivos tenham ajudado no combate ao aparecimento de falhas nas construções, essa problemática ainda é bastante presente, principalmente em obras de habitações populares. As causas podem ser originadas das falhas de projeto, execução e até mesmo pela utilização de materiais inadequados. Neste artigo é identificado os vícios e defeitos construtivos, e os problemas ocorridos no conjunto habitacional "Vitória da Resistência", localizado na cidade de Aracaju- SE, após um ano de ocupação, bem como suas possíveis causas e os efeitos na vida dos moradores. Os principais problemas encontrados foram ausência de reboco e de piso, e a utilização de materiais de baixa qualidade, o que implicou na qualidade construtiva e no desempenho dos imóveis. Os resultados mostram que o conhecimento técnico e o compromisso do profissional responsável em cada etapa são de grande importância para a qualidade e durabilidade da obra, bem como para o conforto e segurança dos usuários de habitações populares.

Palavras-Chave: Defeitos; Durabilidade; Falhas;

\begin{abstract}
Though the progress of the technology and the constructive methods have helped in the fight against the appearing of the flaws in the constructions, this problem is still very present, mainly in the works of the popular habitations. The motives can to be originated of the defects of the projects, execution and maybe the use of the inadequates materials. In this article is identificated the vices and defects constructives, and the problems that they have happened on the housing "Vitória da Resistência", in Aracaju-SE, after one year of the occupation. The main problems encountered were absence of plastering, lack of flooring and the use of poor quality materials, which implies the constructive quality and performance of the properties. The results show that the technical knowledge and the commitment of the responsible professional in each step are of great importance for the quality and durability of the work, as well as for the comfort and safety of the users even in works of popular housing.
\end{abstract}

Key-words: Defects; Durability; Flaws; 


\section{Introdução}

A construção de habitações populares para a população de baixa renda, ou seja, com renda média de até três salários mínimos não é uma problemática recente. Com o crescente desenvolvimento urbano os operários necessitavam morar perto dos seus locais de trabalho levando-os a se instalarem em locais insalubres, pois os seus salários não os permitiam pagar algo melhor. A partir daí as moradias das classes mais baixas passaram a ser vistas como ameaça as condições de higiene das cidades grandes, levando ao afastamento da população mais pobre e o início das construções de habitações populares em lugares mais afastados dos centros urbanos.

No Brasil, em função do seu déficit habitacional, vem sendo construída em grande escala, edificações voltadas para a população de baixa renda e tais construções tem exigido um alto número de manutenção corretiva devido a falhas construtivas encontradas frequentemente, pois tal produção tem seguido um contexto condicionado por fatores sociais e econômicos como construção em grande quantidade ao menor custo possível.

Apesar do avanço da tecnologia e dos métodos construtivos para combater o aparecimento de manifestações patológicas nas construções e garantir a sua qualidade, essa questão ainda é bastante presente na construção civil, principalmente em obras de habitações populares. As falhas vão desde a elaboração de projeto até a falta de manutenção trazendo, muitas vezes, riscos à saúde e segurança dos moradores dos imóveis o que está intimamente ligado à questão de durabilidade. Todas as fases como planejamento, elaboração de projetos, definição de materiais, execução e manutenção colaboram para a prevenção de manifestações patológicas, mas outros fatores importantes são o bom conhecimento técnico e o compromisso por parte do profissional responsável por cada etapa.

Essa pesquisa teve como metas inspecionar a qualidade de habitações populares entregues no bairro Lamarão na cidade de Aracaju- SE, identificar as falhas construtivas surgidas após um ano de utilização, e analisar as possíveis causas e os transtornos que as mesmas têm causado tanto para saúde quanto a segurança dos moradores.

\section{Referencial Teórico}

\subsection{Habitação Popular no Brasil}

A questão habitacional se fez presente desde o final do século XIX, estendendo-se com maior gravidade ao longo do século $\mathrm{XX}$, acompanhando o processo de desenvolvimento urbano, ou seja, a falta de moradia para a população carente no Brasil não é um problema novo na pauta de preocupações da época atual [1].

A oferta habitacional no Brasil, até a década de 1930, era uma responsabilidade do setor privado, sendo assim, as moradias ofertadas estavam voltadas às classes mais ricas. Com o fim da Primeira República, o Estado passou a interferir nessa produção, causando uma marginalização no setor rentista [2]. Em 1964 foi criado o Sistema Financeiro de Habitação (SFH), o mais ambicioso programa governamental para o setor habitacional jamais feito no Brasil, o qual financiou mais de seis milhões de novas habitações em seus mais de trinta anos de existência [3]. O autor [3], ainda comenta que o órgão central do SFH era o BNH (Banco Nacional da Habitação), o qual era responsável pelo gerenciamento do FGTS (Fundo de Garantia do Tempo de Serviço), pela normatização e fiscalização da aplicação dos recursos das cadernetas de poupança, e pela definição das condições de financiamento das moradias para os consumidores finais. Em 28 anos de atuação, o Sistema Financeiro da Habitação financiou a construção de 4,3 milhões de novas moradias, destas 2,4 milhões com recursos oriundos do FGTS para o setor popular, e 1,9 milhões com recursos do SBPE (Sistema Brasileiro de Poupança e Empréstimo) [4].

No início do governo Lula, 2003, o Ministério das Cidades foi criado com a responsabilidade de elaborar a Política Nacional de Desenvolvimento Urbano, incluindo uma nova política para o setor da habitação e no mesmo período, em 2005, foi criado o Fundo Nacional de Habitação de Interesse Social (FNHIS) que tem como objetivo somar todos os recursos para ações voltadas à habitação e direcioná-los para o atendimento às famílias de baixa renda, assim como novos programas de incentivo à construção e financiamento de 
habitações populares, como o Crédito Solidário em 2004, O PAC (Programa de Aceleração do Crescimento) Urbanização de Favelas em 2007 e o Programa Minha Casa, Minha Vida (PMCMV) em 2009, mostrando a existência de uma Política Nacional de Habitação [5].

\subsection{Durabilidade na Construção}

De acordo com a Norma Brasileira 15575-2 [6], durabilidade do sistema estrutural é conservar a segurança, estabilidade e aptidão em serviço durante o período correspondente à sua vida útil. $A$ durabilidade não depende exclusivamente da propriedade do material, mas também do conhecimento das construtoras, pois muitas vezes a falta do mesmo faz com que os componentes produzidos não tenham uma durabilidade muito boa em um determinado ambiente [1].

A durabilidade de uma estrutura de concreto armado é a capacidade de a estrutura conservar as suas características estruturais e funcionais originais pelo tempo de vida útil esperado, nas condições de exposição para as quais foi projetada [7]. Em relação à durabilidade nas construções das habitações populares o autor [1] diz que, "tanto o governo como a sociedade poderão se beneficiar com o aumento da durabilidade, pois, se o governo investir numa habitação popular durável obterá uma redução com os custos de manutenção e reposição das obras de baixa durabilidade".

\subsection{Qualidade na Construção}

O conceito da qualidade evolui sempre acompanhando o ritmo das mudanças [8] e como podemos observar no quadro 1 o que ontem parecia certo, hoje já é ultrapassado.

Quadro 1: Posturas em relação à qualidade

\begin{tabular}{|l|l|}
\hline \multicolumn{1}{|c|}{ ERRADO } & \multicolumn{1}{c|}{ CERTO } \\
\hline $\begin{array}{l}\text { Obras de qualidade são } \\
\text { luxuosas, caras e bonitas. }\end{array}$ & $\begin{array}{l}\text { Obras de qualidade atendem } \\
\text { às expectativas do cliente e } \\
\text { necessidades do usuário. }\end{array}$ \\
\hline $\begin{array}{l}\text { Qualidade é conceito vago, } \\
\text { subjetivo, impossível de } \\
\text { medir; você só conhece } \\
\text { quando vê. }\end{array}$ & $\begin{array}{l}\text { Qualidade consiste no } \\
\text { cumprimento dos requisitos } \\
\text { e especificações do cliente. }\end{array}$ \\
\hline
\end{tabular}

\begin{tabular}{|l|l|}
\hline $\begin{array}{l}\text { Qualidade implica inspeção } \\
100 \% \text {, consertar o que saiu } \\
\text { errado. }\end{array}$ & $\begin{array}{l}\text { Qualidade é prevenir } \\
\text { ocorrência de erros ou } \\
\text { desvios em relação às } \\
\text { especificações nas várias } \\
\text { etapas do processo de } \\
\text { produção. }\end{array}$ \\
\hline $\begin{array}{l}\text { Qualidade é função da } \\
\text { produção, responsabilidade } \\
\text { do departamento de } \\
\text { controle da qualidade. }\end{array}$ & $\begin{array}{l}\text { A responsabilidade pela } \\
\text { qualidade é compartilhada } \\
\text { por todos e exige total } \\
\text { envolvimento dos } \\
\text { funcionários. }\end{array}$ \\
\hline $\begin{array}{l}\text { Indicadores da } \\
\text { produtividade já dão a } \\
\text { medida da qualidade. }\end{array}$ & $\begin{array}{l}\text { Indicadores da qualidade } \\
\text { medem a satisfação do } \\
\text { cliente; indicadores da } \\
\text { produtividade medem a } \\
\text { eficiência no uso de recursos. }\end{array}$ \\
\hline $\begin{array}{l}\text { Desperdício elevado e } \\
\text { presença de patologias na } \\
\text { construção são aceitáveis, } \\
\text { são características próprias } \\
\text { do setor. }\end{array}$ & $\begin{array}{l}\text { Não se conformar com } \\
\text { perdas e erros; promover } \\
\text { melhorias contínuas, visando } \\
\text { minimizar os desperdícios e } \\
\text { erros em patamares cada vez } \\
\text { mais inferiores. }\end{array}$ \\
\hline $\begin{array}{l}\text { Qualidade só pode ser } \\
\text { introduzida na empresa } \\
\text { através da contratação de } \\
\text { especialistas no assunto. } \\
\text { Qtravés da liderança dos } \\
\text { dirigentes da empresa e do } \\
\text { comprometimento de todos } \\
\text { os seus funcionários. }\end{array}$ \\
\hline $\begin{array}{l}\text { Fonte: Souza (1995). } \\
\text { atada será alcancada }\end{array}$ \\
\hline
\end{tabular}

Fonte: Souza (1995).

Tendo em vista a necessidade de implantação dos sistemas de qualidade, foi lançado em 1992, o Programa Brasileiro de Qualidade e Produtividade no Habitat - PBQP-H, que é dividido em quatro níveis de certificação ( $D, C, B$ e $A)$, e contempla os mesmos requisitos da ISO 9000. O programa visa alcançar todos os setores da construção civil ao longo da cadeia produtiva, apoiar o esforço brasileiro de modernização por meio da melhoria da qualidade, do aumento da produtividade e da redução de custos na construção habitacional [9]. É na etapa de projeto que acontece a concepção e o desenvolvimento do produto. A qualidade da solução do projeto determinará a qualidade do produto e, consequentemente, condicionará o grau de satisfação dos usuários finais [10].

Em relação à qualidade do material, o autor [11] fala que na construção civil, deve-se praticar o sistema de "compra técnica", levando em consideração requisitos de desempenho, previsão da vida útil, custos de reposição e de manutenção do produto, portanto, as compras devem ser feitas por profissional habilitado. O autor ainda fala sobre a importância da etapa de planejamento para obter uma obra de qualidade, pois se os projetos convencionais estabelecem "o que fazer" e "com quais materiais", resta definir "como fazer", "quem vai fazer", "onde e quando vai ser feito" e isso envolve projeto da produção,

http: / / dx.doi.org/10.25286/repa.v2i3.693 
englobando organização do canteiro, detalhamento dos processos, dimensionamento das equipes, definição de equipamentos $e$ ferramentas, subcontratações, previsão das medidas de segurança, estabelecimento dos planos de inspeções e ensaios, concatenação das fases e etapas de construção num cronograma coerente no espaço e no tempo.

Checar a execução dos serviços evita a ocorrência de problemas nas etapas posteriores e garante a qualidade da obra como um todo, pois ela só é alcançada com a execução correta de cada serviço em particular [10]. Por fim, se espera que haja uma continuidade no Plano da Qualidade após o início da execução da obra. Essa relação pode ser diferente nos casos de obras públicas, onde geralmente a empresa construtora não estará envolvida desde a primeira etapa do processo, ou dos empreendimentos da iniciativa privada. Nesse último caso, é desejável a participação da equipe da construtora desde a fase de anteprojeto [12].

\subsection{Patologia na Construção Civil}

Patologia pode ser entendida como "a parte da Engenharia que estuda os sintomas, os mecanismos, as causas e as origens dos defeitos das construções civis, ou seja, é o estudo das partes que compõem o diagnóstico do problema" [13].

Em relação aos vícios, a NBR 13752 [14] define como anomalias que afetam o desempenho de produtos ou serviços, ou os tornam inadequados aos fins a que se destinam, causando transtornos ou prejuízos materiais ao consumidor. Os vícios podem decorrer de falha de projeto ou de execução, ou ainda da informação defeituosa sobre sua utilização ou manutenção.

Já em relação aos defeitos a NBR define como anomalias que podem causar danos efetivos ou representar ameaça potencial de afetar a saúde ou segurança do dono ou consumidor, decorrentes de falhas do projeto ou execução de um produto ou serviço, ou ainda de informação incorreta ou inadequada de sua utilização ou manutenção. Estudos mostram que um elevado percentual dos problemas patológicos nas edificações é originado nas fases de planejamento e projeto e essas falhas são geralmente mais graves que as relacionadas à 104 qualidade dos materiais e aos métodos construtivos. Isso se explica pela falta de investimento dos proprietários, sejam eles públicos ou privados, em projetos mais elaborados e, detalhados, fazendo com que a busca pura e simples de projetos mais "baratos" implique muitas vezes na necessidade de adaptações durante a fase de execução e futuramente em problemas de ordens funcional e estrutural [15]

No Brasil, as principais causas das patologias estão relacionadas à execução, como mostra o gráfico 1 [16]. Mesmo que as etapas anteriores sejam realizadas com sucesso, a obra pode apresentar patologias originadas pelo uso, pois a má utilização da edificação ou a falta de manutenção adequada pode implicar na qualidade e na segurança [17].

Gráfico 1: Incidência de Patologia no Brasil.

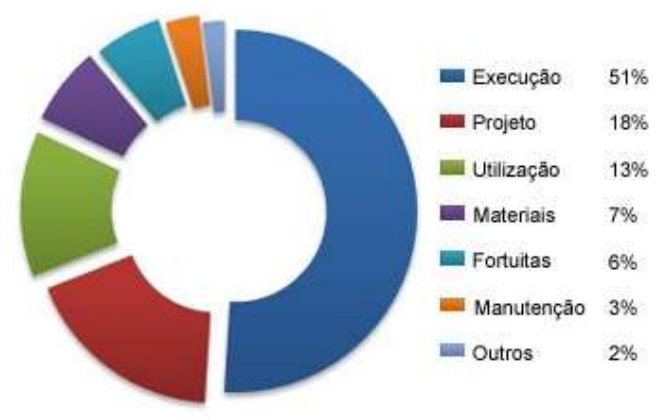

Fonte: http://www.aecweb.com.br (2015).

\section{Metodologia}

Essa pesquisa foi desenvolvida no conjunto habitacional Vitória da Resistência, situado na cidade de Aracaju, estado de Sergipe, no bairro Lamarão (zona norte da capital), produzido pela prefeitura de Aracaju com recursos do Governo Federal tendo como objetivo beneficiar às famílias que antes viviam em barracos na Invasão da Salina de São Marcos. Os imóveis começaram a ser entregues à população no dia 7 de setembro de 2014 através da Secretaria Municipal de Infraestrutura e da Secretaria Municipal da Família e Assistência Social de Aracaju- SE.

O conjunto tem um total de 410 habitações populares, sendo 21 casas adaptadas, e as unidades são compostas de dois quartos, um banheiro, uma sala e uma cozinha. Para realização 
desse estudo, foi dado início a inspeção em campo onde foram feitas entrevistas com moradores através de um questionário elaborado pelo autor, mostrado no quadro 2 .

Quadro 2: Questionário

1-Há quanto tempo habita o imóvel?
2-Quando o imóvel foi entregue, foi observada a existência de
algum problema que comprometesse sua qualidade? Quais?
3-Se a resposta inicial for positiva, cite se houve agravamento
ou aparecimento do mesmo problema em outras partes do
imóvel durante o período de habitação.
4-Verificou o surgimento de outros problemas durante o
período de habitação? Quais?
5-O usuário se recorda de algum fato que possa estar ligado
ao aparecimento do (s) problema (s) observado (s)?
6-Você atribui o aparecimento do problema ou agravamento
do mesmo devido às condições climáticas (por exemplo,
períodos chuvosos) ou a algum problema de funcionamento
próprio do imóvel, como vazamentos?
7-Já foram realizadas medidas para sanar e/ou prevenir o
agravamento ou aparecimento dos problemas citados?
8-O usuário encontra-se satisfeito com a qualidade do imóvel?
( ) SIM ( ) NÃO
9-Qual a causa da insatisfação?
( ) LOCALIZAÇÃO ( ) FALTA DE INFRAESTRUTURA ( ) FALTA
DE CONFORTO ( ) OUTROS
10-Sonho da casa própria atendido? ( ) SIM

Fonte: Elaborado pelo autor (2015).

As vistorias foram realizadas em $10 \%$ do total das habitações (41 casas). Estas escolhidas aleatoriamente para análise de forma a abranger uma amostragem representativa de casas em relação a localização e posição. As visitas foram realizadas em três dias distintos, sábado à tarde (dia 11 de abril de 2015), quarta-feira à tarde (dia 13 de maio de 2015) e na segunda-feira pela manhã (08 de junho de 2015). Todas as informações obtidas no local através do questionário foram acumuladas e organizadas para o entendimento dos problemas encontrados. As casas escolhidas para coleta de dados encontram-se ilustradas na figura 1 .

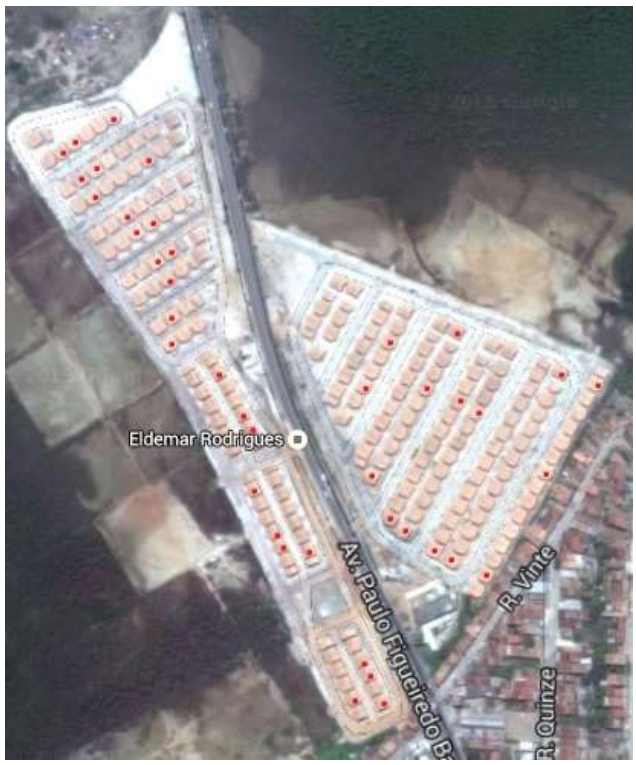

Figura 1: Casas escolhidas para coleta de dados. Fonte: Google maps (2015).

\section{Resultados}

De forma geral, os imóveis apresentaram diversos problemas como: ausência de reboco, ausência de piso, ausência de pintura, umidade, problema nas instalações do banheiro, problema no telhado, utilização de materiais de baixa qualidade, entre outros. De todos os problemas citados, os que mais revoltam os moradores são a falta de reboco no interior das casas e a falta de piso, pois todas as casas do conjunto foram entregues sem piso e sem reboco.

A ausência de piso no interior das residências (figura 2) causa diversos transtornos à saúde e ao conforto dos moradores, pois o pó do cimento já levou muitas crianças a apresentarem quadros de alergia e até pneumonia por estarem expostas à poeira. Alguns moradores optaram por colocar piso por conta própria, pois nada foi feito em relação a isso por parte dos responsáveis pela obra das habitações. 


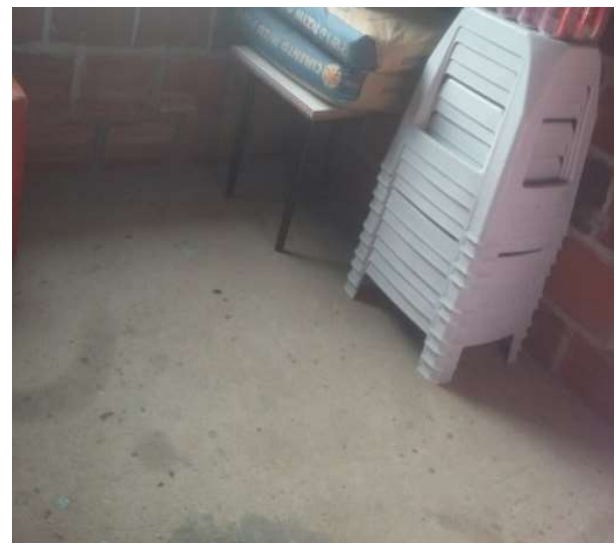

Figura 2: Ausência de piso.

Fonte: Elaborado pelo autor (2015).

Além da falta de piso, outro problema geral é a falta de reboco, pois todas as casas visitadas foram entregues sem reboco, como mostra a figura 3 . O reboco e a pintura só foram feitos na fachada das casas, nas laterais foram aplicados apenas chapisco (figura 4).

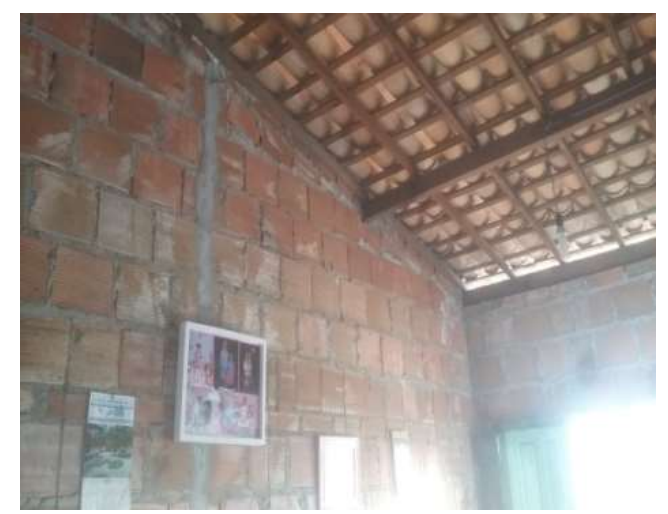

Figura 3: Ausência de reboco.

Fonte: Elaborado pelo autor (2015).

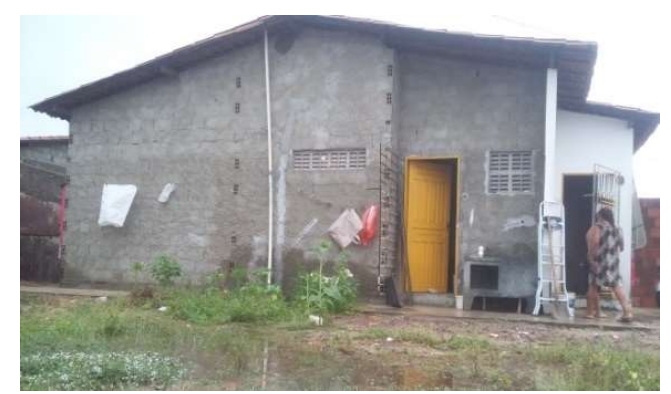

Figura 4: Vista Lateral.

Fonte: Elaborado pelo autor (2015).

Vários foram os problemas encontrados em relação às portas e janelas, pois muitas delas se encontram com problema na fechadura (figura 5) causando falta de segurança aos moradores, levando-as a tomar atitudes para diminuir a insegurança, e também empenadas e inchadas (figura 6) devido à água que entra pelas mesmas quando chove.

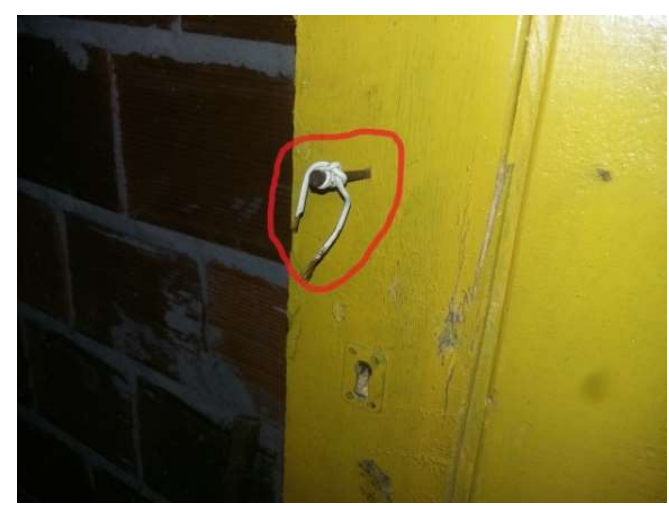

Figura 5: Fechadura da porta.

Fonte: Elaborado pelo autor (2015).

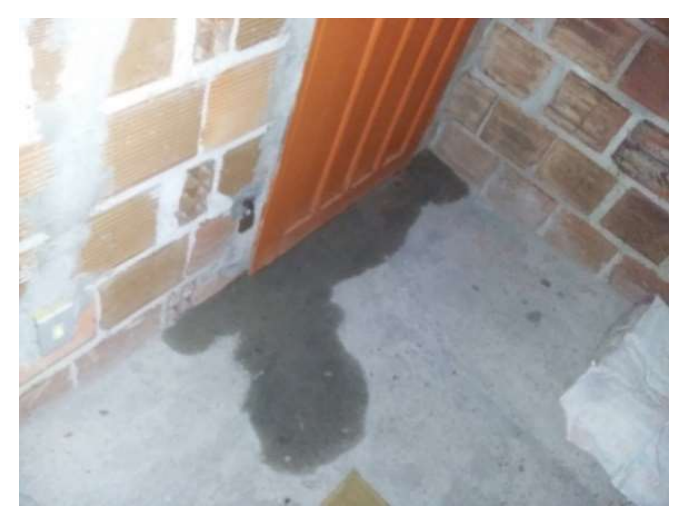

Figura 6: Invasão da água da chuva. Fonte: Elaborado pelo autor (2015).

Os moradores relataram que quando chove as portas não fecham e eles precisam improvisar fechaduras para se sentirem seguros. Empregar materiais de baixa qualidade e com vedação insuficiente pode acarretar problemas como infiltrações de água da chuva e consequentes manchas e bolores em paredes e pisos próximos às janelas e portas, portanto a possível causa dos problemas encontrados em relação a portas e janelas é devido à utilização de materiais de baixa qualidade, pois com menos de um ano de utilização já se encontram deterioradas e impróprias para uso.

Em $46 \%$ das casas os moradores relataram que a água que sai do chuveiro empoça e até escorre para os quartos quando na verdade deveria descer pelo ralo. Isso apresenta uma possível falha nas 
etapas de projeto e/ou execução, pois deve ser especificado em projeto o nível do banheiro mais baixo que o nível da área de circulação, impossibilitando o escorrimento da água para outros cômodos. Após a execução da superfície, deve ser feita a verificação da eficiência do caimento, por meio de instrumentos simples, como o indicador de nível para garantir o perfeito funcionamento.

A falta de acessórios também foi observada durante a pesquisa. Em 12\% das casas visitadas os moradores relataram ter recebido sem a torneira da pia da cozinha e do banheiro (figura 7) e também sem o sifão da pia da cozinha, tendo que realizar o reparo para utilizá-la.

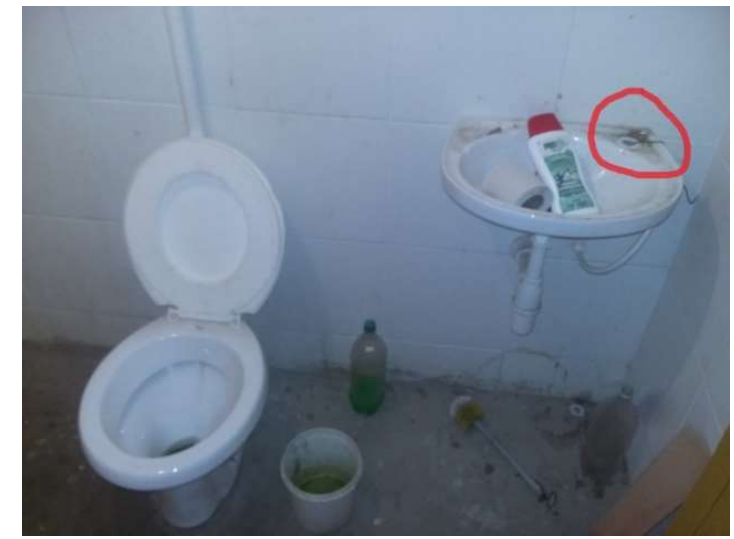

Figura 7: Pia sem torneira.

Fonte: Elaborado pelo autor (2015).

Outro problema que foi observado em $90 \%$ das casas está relacionado ao telhado. Os moradores relataram que há muita goteira e que essas goteiras causaram muitos prejuízos, pois alguns já perderam inclusive eletrodomésticos. A causa do aparecimento dessas goteiras foi, possivelmente, devido à má execução do madeiramento do telhado, e da utilização de números de telhas insuficientes o que resultou num cobrimento inadequado. Esse tipo de problema pode resultar em patologias futuras como eflorescência, manchas de umidade, apodrecimento do madeiramento, entre outras. Para sanar o problema, os próprios moradores fizeram os reparos no telhado.

Um aspecto que também pôde ser observado é presença de umidade nas paredes (figura 8) de algumas casas, isto devido fato do solo da região em que foi construído o habitacional ser um solo úmido, o que se agrava em dias de chuva, resultando em uma patologia chamada de umidade por capilaridade. A presença de umidade nas paredes pode ter sido ocasionada pela não impermeabilização da base da parede ou até a má execução da mesma.

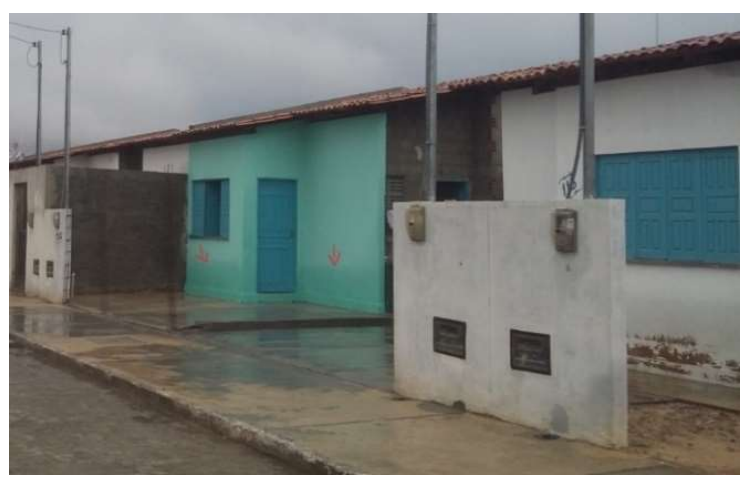

Figura 8: Umidade nas paredes.

Fonte: Elaborado pelo autor (2015).

No gráfico 2 encontram-se sumarizados os resultados das visitas realizadas as 41 casas do conjunto habitacional, bem como os resultados estatísticos dos problemas encontrados no conjunto habitacional para as casas inspecionadas.

Gráfico 2: Representação gráfica da estatística dos problemas observados.

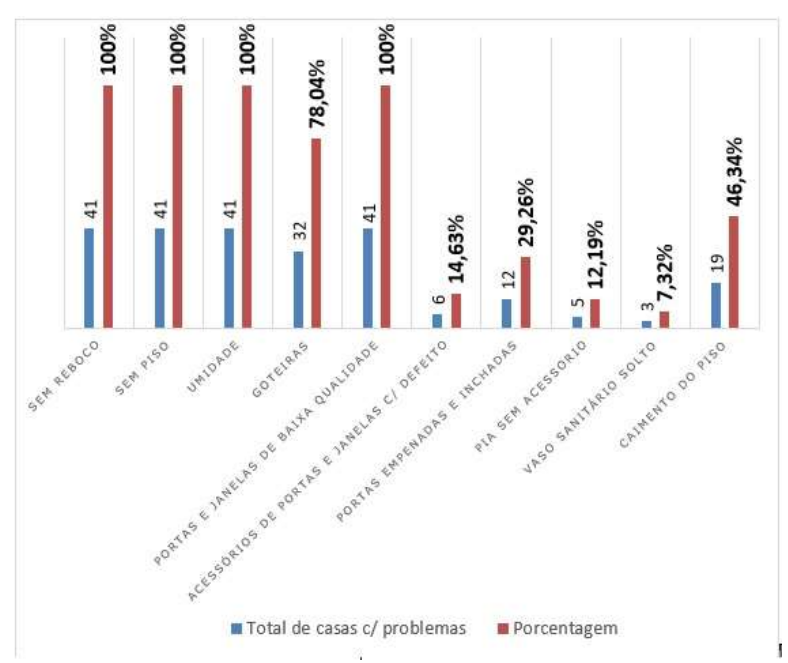

Fonte: Elaborado pelo autor (2015).

Ainda com o intuito de compreender melhor o nível de insatisfação dos morados foi realizada uma pesquisa de satisfação. Nesta pesquisa, surpreendentemente, a maioria dos moradores disse estar satisfeito com a nova moradia, mas os

http: / / dx.doi.org/10.25286/repa.v2i3.693 
reais motivos estão relacionados com o fato deste local "ser melhor do que morar em um barraco" segundo a fala dos moradores. Porém, todos corroboram que a insatisfação está nas condições em que as casas foram entregues, não apresentando qualidade nenhuma, falta de conforto, localização ruim e falta de infraestrutura.

Os moradores também foram questionados sobre a realização por parte dos responsáveis pela obra de alguma medida para sanar ou prevenir o agravamento e o aparecimento dos problemas citados. Unanimemente os entrevistados responderam que por parte dos responsáveis pela obra até agora nada foi feito e que os consertos, para não agravar a situação, têm sido realizados pelos próprios moradores.

A fim de entender melhor a problemática da situação de entrega das residências, bem como das falhas construtivas encontradas o fiscal da Empresa Municipal de Obras e Urbanização (EMURB), também foi entrevistado. Segundo ele, os moradores já haviam sido informados desde o início que iriam receber as casas sem reboco e sem piso e que a responsabilidade dos acabamentos finais seria dos próprios moradores. Questionado sobre o fato das casas terem sido entregues há menos de um ano e já apresentarem deterioração de alguns materiais utilizados, como portas e janelas, o fiscal respondeu que os materiais utilizados na obra não são de primeira qualidade e que a verba disponibilizada para a obra das habitações populares foi curta, portanto os materiais utilizados foram o que couberam no orçamento. Porém, reforçou que durante dois meses após a entrega das chaves a construtora responsável pela execução dos serviços esteve disponível no local para realizar reparos. Ele ainda salientou que todas as falhas decorridas nesses dois meses foram corrigidas, porém não foram apresentados registros de controle de qualidade dos materiais utilizados ou da execução da obra.

\section{Conclusões}

Foi abordada neste estudo a qualidade das habitações populares entregues há menos de um ano à população de baixa renda do Conjunto Habitacional Vitória da Resistencia, Aracaju- SE. De forma geral, são notórias as falhas construtivas decorrentes de execução e da utilização de materiais de baixa qualidade. A ausência de 108 reboco e piso nas casas demonstrou que as mesmas não foram entregues prontas para morar, não apresentando o mínimo de conforto que uma moradia digna pode oferecer.

O Art. 618 do Código Civil de 2002 assegura que nos contratos de empreitada de edifícios ou outras construções consideráveis, o empreiteiro de materiais e execução responderá, durante o prazo irredutível de cinco anos, pela solidez e segurança do trabalho, assim em razão dos materiais, como do solo. Portanto, os moradores dos imóveis apresentados têm total direito no que diz respeito aos reparos no prazo de cinco anos que nesse caso deveria ser de responsabilidade da construtora e não contratante (EMURB).

Os resultados estatísticos apresentados revelam que em $100 \%$ das casas não foram colocados piso e reboco, em $90 \%$ foram encontradas goteiras e em $100 \%$ das casas foram utilizados materiais de baixa qualidade em relação a portas e janelas, dentre outras falhas construtivas detectadas em menor escala. Este estudo demonstrou que todas as fases de um processo construtivo como projeto, execução e qualidade dos materiais utilizados devem ser respeitadas, pois a má execução de uma dessas etapas pode ocasionar transtornos à saúde dos moradores bem como prejuízos financeiros. O padrão de qualidade deve ser seguido também para habitações populares oferecendo uma habitação segura, acessível, durável e que promova bemestar e conforto aos seus usuários.

\section{Referências}

[1] PINA, Gregório Lobo de. Patologia nas Habitações Populares. 2013. 102 f. TCC (Graduação) - Curso de Engenharia Civil, Universidade Federal do Rio de Janeiro, Rio de Janeiro, 2013.

[2] BOTELHO, Adriano. O urbano em fragmentos: a produção do espaço e da moradia pelas práticas do setor imobiliário. São Paulo: Annablume; Fapesp, 2007.

[3] SANTOS, Cláudio Hamilton M.. Políticas Federais de Habitação no Brasil: 1964/1998. Brasília: Ipea, 1999. 
[4] ARRETCHE, M. (2000) Estado Federativo e Políticas Sociais: Determinantes da Descentralização. 1 ed. Rio de Janeiro: Revan.

[5] BALBIM, Renato; KRAUSE, Cleandro. Produção social da moradia: um olhar sobre o planejamento da Habitação de Interesse Social no Brasil. Revista Brasileira de Estudos Urbanos e Regionais, Recife, v. 16, n. 1, p.189-201, maio 2014. Semestral.

$\begin{array}{lcr}\text { [6] ASSOCIAÇÃO BRASILEIRA DE NORMAS } & \text { DÉ } \\ \text { TÉCNICAS. NBR } & \mathbf{1 5 5 7 5 - 2 :}\end{array}$ habitacionais - Desempenho Parte 2: Requisitos para os sistemas estruturais. Rio de Janeiro, 2013.

[7] OLIVEIRA, Daniel Ferreira. Levantamento de causas de patologias na construção civil. 2013. 107 f. TCC (Graduação) - Curso de Engenharia Civil, Universidade Federal do Rio de Janeiro, Rio de Janeiro, 2013.

[8] SOUZA, Roberto de et al. Sistema de Gestão da Qualidade para Empresas Construtoras. São Paulo: Pini, 1995.

[9] SILVEIRA, Débora et al. Qualidade na construção civil: um estudo de caso em uma empresa da construção civil no rio grande do norte. In: Encontro Nacional de Engenharia de Produção, 22, 2002, Curitiba.

[10] SOUZA, Roberto de; ABIKO, Alex. Metodologia para Desenvolvimento e Implantação de Sistemas de Gestão da Qualidade em Empresas Construtoras de Pequeno e Médio Porte. São Paulo: Escola Politécnica da Usp/departamento de Engenharia de Construção Civil, 1997.

[11] THOMAZ, Ercio. Tecnologia, Gerenciamento e Qualidade na Construção. São Paulo: Pini, 2001. 331-341 p.

[12] MELHADO, Silvio (1999). O plano da qualidade dos empreendimentos e a engenharia simultânea na construção de edifícios. São Paulo. Escola Politécnica da Universidade de São Paulo.
[13] HELENE, P. R. L. Manual para reparo, reforço e proteção de estruturas de concreto. 2. ed. São Paulo: PINI, 1992.

[14] ASSOCIAÇÃO BRASILEIRA DE NORMAS TÉCNICAS. NBR 13752: Perícias de engenharia na construção civil. Rio de Janeiro: Abnt, 1996.

[15] VITÓRIO, Afonso. Fundamentos da patologia das estruturas nas perícias de engenharia. Recife: Instituto Pernambucano de Avaliações e Perícia de Engenharia, 2003.

[16] AECWEB, Redação; PIANCASTELLI, Élvio Mosci. Patologias do concreto. Disponível em: <https://www.aecweb.com.br/cont/m/rev/patolo gias-do-concreto_6160_0_1>.Acesso em: $10 \mathrm{abr}$. 2015.

[17] IANTAS, Lauren Cristina. Estudo de caso: análise de patologias estruturais em edificação de gestão pública. 2010.58 f. Monografia (Especialização) - Curso de Curso de Pós Graduação em Construção de Obras Públicas, Universidade Federal do Paraná, Curitiba, 2010. 